\title{
New tool evaluates risk of patient aggression
}

A

free electronic tool that tracks changes in a patient's likelihood of becoming violent could revolutionize how health care workers manage aggression.

The electronic Hamilton Anatomy of Risk Management tool, or e-HARM, walks users through a four-step evaluation of past and present factors to determine a patient's future risk for violence. The tool's developers at St. Joseph's Healthcare Hamilton in Ontario have done this kind of guided risk assessment on paper for almost a decade. Unlike paper-based predecessors, however, the e-HARM aggregates and charts the data it captures over time. This allows clinicians to instantly graph an individual's or a group's history of aggression against changes in other factors, like medication adherence.

The tool represents an "absolute breakthrough in forensic mental health," and a version for use in general psychiatry is on its way, says Dr. Gary Chaimowitz, who heads St. Joseph's forensic

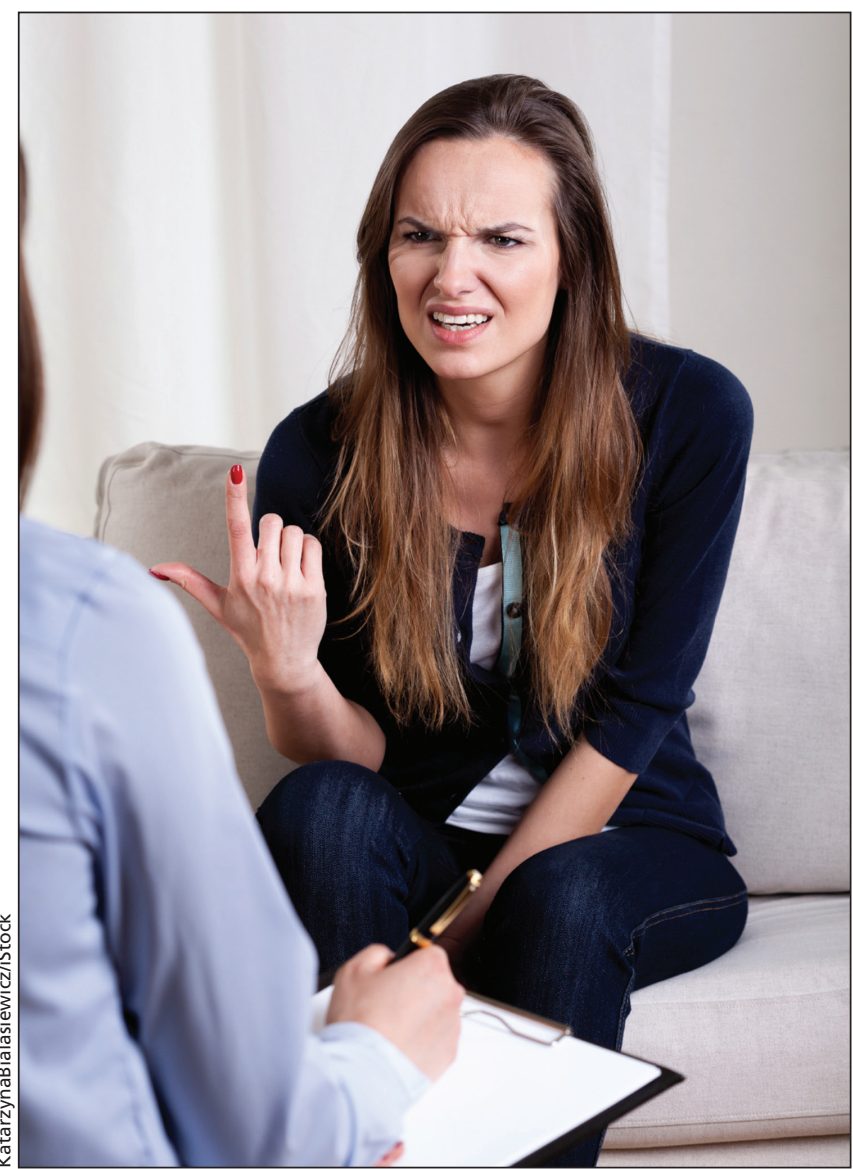

St. Joseph's Healthcare Hamilton in Ontario has developed a new tool for assessing and managing patient aggression.

work, Chaimowitz says. There is also "amazing research potential" because the e-HARM tool can aggregate and analyze data from multiple patients, units or institutions.

"With a click of a button, I can tell you how many people with a specific diagnosis I have on the unit, what programs they're using and what seems to be effective," he explains. "In terms of quality improvement, we're going to be light-years ahead."

The forensic version of the tool is already attracting interest from health workers across Canada. In addition to training sessions in Hamilton and North Bay, Ontario, St. Joseph's has run workshops in Vancouver and Winnipeg.

Still, not everyone is eager to apply a big data approach to mental health care. According to Chaimowitz, "some people feel that it may take away some of their independence around decision-making."

Others at a recent Risk psychiatry program. "Clinically, we're now in a better position to understand patients, their risks and the roads to recovery."

Frontline workers in the forensic psychiatry program at St. Joseph's now document all aggressive incidents using a 9-point scale. This captures everything from rudeness (level one) to life or death incidents involving the police and medical attention for the victim (level nine). The reports also note whether and how health workers intervened following an incident. An example of a patient's monthly chart might show a spattering

of ones or twos, with a three or four leading up to a level seven incident.

The e-HARM tool connects these incident reports to the bigger picture of a patient's history, including past and present diagnoses, behaviour and treatments. Clinicians weigh all these factors using the assessment portion of the tool to capture a patient's evolving risk on a monthly or more frequent basis.

Using the tool's analytic functions, health workers will hopefully be able to spot escalating behaviour before it boils over and measure whether interventions to reduce violence actually and Recovery Forensic Conference in Hamilton questioned whether the information provided by the e-HARM tool might bias health workers against riskier patients.

Chaimowitz says that hasn't been the experience at St. Joseph's, where the tool has been used for several months. "The more knowledge staff had about the person's risk issues, the more comfortable they felt," he says. "It's better to have that information rather than fearing unknowns." - Lauren Vogel, CMAJ

CMAJ 2016. DOI:10.1503/cmaj.109-5276 